Am J Med Sci. 2012 April ; 343(4): 321-326. doi:10.1097/MAJ.0b013e31822fb423.

\title{
Hyperglycemia in Nondiabetic Patients Presenting With Acute Myocardial Infarction
}

\author{
Binita Shah, MD, MS, Nicholas S. Amoroso, MD, Steven P. Sedlis, MD \\ Division of Cardiology, Department of Internal Medicine, VA New York Harbor Health Care \\ System and New York University School of Medicine, New York City, New York.
}

\begin{abstract}
Hyperglycemia is common in nondiabetic patients with acute myocardial infarction (AMI).

Elevated blood glucose level may reflect a response to stress, an underlying abnormal glucometabolic state or both. Regardless of mechanism, hyperglycemia complicating AMI is associated with an inflammatory and prothrombotic state, depressed myocardial contractility and increased short- and long-term mortality. Studies are needed to define optimal monitoring and management of hyperglycemia in nondiabetic patients with AMI.
\end{abstract}

\section{Key Indexing Terms:}

Hyperglycemia; Nondiabetic; Acute myocardial infarction; Diabetes mellitus

\begin{abstract}
Hyperglycemia is common and has independent adverse prognostic significance in patients with acute myocardial infarction (AMI) even in patients without a history of diabetes mellitus. Hyperglycemia in the setting of AMI may be transient and stress induced, rather than a reflection of the underlying glucometabolic state, but the mechanisms have not been fully elucidated and the evaluation and management of these patients remain both challenging and uncertain. Recently, the American College of Physicians published clinical practice guidelines addressing the use of intensive insulin therapy for the management of hyperglycemia in hospitalized patients with and without diabetes. ${ }^{1}$ However, these guidelines emphasize that the evidence base is less robust in the AMI population than in other groups. Furthermore, the American College of Cardiology/American Heart Association guidelines, which do recommend glycemic control in the AMI setting, do not address the best method of treatment, how to manage elevated blood glucose levels that are less than $180 \mathrm{mg} / \mathrm{dL}$, how often blood glucose levels should be monitored or how to follow nondiabetic patients who have had hyperglycemia in the setting of AMI after discharge. ${ }^{2}$ The purpose of this review is to summarize the literature on hyperglycemia in nondiabetic patients presenting with AMI, to make evidence-based recommendations for management and to suggest possible avenues for further investigation.
\end{abstract}

Correspondence: Steven P. Sedlis, MD, Division of Cardiology, 12 West, VA New York Harbor Health Care System New York, 423 East 23rd Street, New York City, NY 10010 (steven.sedlis@ va.gov). 


\section{Incidence of Stress Hyperglycemia and Unrecognized Diabetes in AMI}

As early as 1929 , Levine ${ }^{3}$ wrote that "glycosuria is a common occurrence during the acute stage of coronary thrombosis, that it may be only transitory, and that it need not indicate any important diabetic state." More recently, Haffner et al ${ }^{4}$ suggested that hyperglycemia in nondiabetic AMI patients may reflect a prediabetic state, whereas others proposed that hyperglycemia in this setting may be due to previously undiagnosed diabetes. ${ }^{5-7}$ However, there has been little evidence supporting the association between the duration of diabetes and macrovascular disease. Furthermore, because glycosylated hemoglobin (HbA1c) was not measured in early studies, it is unknown whether patients in those studies had chronically impaired glucose control or stress-induced hyperglycemia. ${ }^{4-7}$

In 1975, Ravid et al ${ }^{8}$ evaluated 169 nondiabetic AMI patients. Fasting blood glucose level was elevated (>120 mg/dL) in $47 \%$ of the patients. At 6 years, $80 \%$ of surviving patients with elevated admission fasting blood glucose levels developed diabetes, whereas $5 \%$ of surviving patients with normal admission fasting blood glucose levels had abnormal oral glucose tolerance tests. The authors concluded that elevated fasting blood glucose levels in nondiabetic AMI patients predicted subsequent development of diabetes.

More recent studies used HbA1c to distinguish stress-induced hyperglycemia from unrecognized diabetes in patients with AMI. ${ }^{9,10}$ In 1981, Soler and Frank ${ }^{9}$ prospectively evaluated 99 nondiabetic AMI patients. Approximately one third of these patients had elevated fasting blood glucose levels ( $\geq 140 \mathrm{mg} / \mathrm{dL}$ ), but only $13 \%$ had elevated HbA1c levels (>8.5\%) consistent with undiagnosed diabetes. At 3-month follow-up, repeat fasting blood glucose levels correlated with the original HbA1c levels. The authors concluded that HbA1c identified the cohort with undiagnosed diabetes. Similarly in 1984, Lakhdar et al ${ }^{10}$ studied 61 nondiabetic AMI patients and found that 33\% of these patients had hyperglycemia with normal HbAlc levels $(<7 \%)$. Only $17 \%$ of patients with hyperglycemia and normal $\mathrm{HbA} 1 \mathrm{c}$ on admission were diagnosed with diabetes 3 months later.

A more contemporary study from 2001 by Tenerz et $\mathrm{al}^{11}$ measured admission HbA1c and fasting blood glucose level on hospital days 2 and 5 in 285 patients presenting with AMI. Measurements, including an oral glucose tolerance test, were repeated at 2- to 3-month follow-up. In the 172 nondiabetic patients, 3 times as many patients were observed to have an in-hospital fasting blood glucose level of $\geq 110 \mathrm{mg} / \mathrm{dL}$ than on follow-up, suggesting hyperglycemia was related to the stress of AMI rather than undiagnosed diabetes. Using diagnostic criteria consistent with the most recent definition of diabetes, ${ }^{12}$ Norhammar et al's 2002 prospective study of 181 nondiabetic AMI patients and an admission glucose level of $<200 \mathrm{mg} / \mathrm{dL}$ demonstrated a high prevalence of impaired glucose tolerance and undiagnosed diabetes (35\% and 31\%, respectively). Furthermore, admission HbA1c and fasting blood glucose level on day 4 of hospitalization were shown to be independent predictors of abnormal glucose tolerance at 3-month follow-up, and thus identifying patients at high risk for diabetes. 
Based on the literature, approximately $10 \%$ to $20 \%$ of nondiabetic AMI patients have significant hyperglycemia. Thus, up to 100,000 admissions of nondiabetic patients with AMI in the United States are complicated by hyperglycemia yearly.

\section{Pathophysiology}

Hyperglycemia during AMI may be due to stress with increased release of catecholamines, 13-15 steroids, ${ }^{16-18}$ and glucagon ${ }^{19,20}$ and decreased release of insulin. ${ }^{21,22}$ Insulin deficiency is relative but is also the result of partial inhibition of pancreatic beta-cells by a stress-induced rise in catecholamines. ${ }^{23}$ Oswald et al ${ }^{24}$ examined blood glucose level, $\mathrm{HbA1c}$, cortisol and catecholamine concentrations in 27 nondiabetic AMI patients. Multiple regression analysis showed cortisol, adrenaline and noradrenalin to be the main determinants of admission blood glucose levels in this population. Whether this endocrine response is due to extensive infarction or severe myocardial dysfunction or both is unclear.

\section{Prothrombotic and Inflammatory Effects}

Hyperglycemia in the setting of AMI predisposes to thrombus formation ${ }^{25}$ with increased platelet activity, aspirin resistance ${ }^{26}$ and impaired fibrinolysis. ${ }^{27-29}$ Acute hyperglycemia correlates with endothelial dysfunction, ${ }^{30,31}$ oxidative stress, ${ }^{32,33}$ proinflammatory changes with increased cytokine and adhesion molecule production ${ }^{34,35}$ and no-reflow in patients with AMI. ${ }^{36}$ Inflammation associated with acute hyperglycemia during AMI is linked to particularly poor cardiac outcome. ${ }^{37}$ Tight glycemic control, in turn, reduces oxidative stress and inflammation and possibly has beneficial effects on remodeling in hyperglycemic patients during AMI. ${ }^{38}$

\section{Effects on Myocardial Contractility}

Acute hyperglycemia attenuates ischemic preconditioning by decreasing the activity of KATP channels. ${ }^{39}$ Hyperglycemia also leads to osmotic diuresis and reduced stroke volumes through the Frank-Starling mechanism. ${ }^{40}$ Furthermore, relative insulin deficiency and excess catecholamines reduce glucose uptake by ischemic myocardium and increase free fatty acid levels, which are toxic to ischemic myocardium. ${ }^{41}$ Animal studies have shown that increased myocardial uptake and metabolism of glucose during ischemia correlates with preservation of myocardial function, ${ }^{42}$ whereas increased free fatty acid levels increase myocardial oxygen demand and reduce myocardial contractility. ${ }^{43}$

\section{Prognosis}

\section{Significance of Admission Blood Glucose Level}

Many studies have demonstrated that hyperglycemia in the setting of AMI is an independent predictor of heart failure and mortality regardless of diabetic status. $6,7,24,44-52$ This observation holds true in the current era, and higher glucose levels are associated with worse ejection fraction and higher mortality regardless of reperfusion strategy. ${ }^{7,48-51}$ Studies evaluating the prognostic significance of admission glucose levels in nondiabetic AMI patients on heart failure and mortality are summarized in Table 1. Of interest, 2 of these studies showed that nondiabetic AMI patients with hyperglycemia have higher mortality 
than diabetic AMI patients with hyperglycemia. ${ }^{6,52}$ This may be explained by less aggressive medical treatment in the nondiabetic cohort, underscoring the importance of identifying and adequately treating hyperglycemia in nondiabetic AMI patients.

\section{Significance of Fasting Blood Glucose Level}

There are 3 studies evaluating the relationship of fasting blood glucose level with mortality in nondiabetic patients after AMI (Table 2). ${ }^{53-55}$ Of interest, Suleiman et al ${ }^{53}$ noted that the addition of fasting blood glucose level to a logistic regression model based on admission glucose level improved model prediction but the addition of admission glucose level to a model based on fasting blood glucose level did not. This suggested the superiority of fasting blood glucose level over admission glucose level in the risk assessment of mortality in nondiabetic AMI patients. Furthermore, in 1981, a study by Soler and Frank ${ }^{9}$ showed a poor correlation between admission glucose and $\mathrm{HbA1c}$ level but a strong correlation between fasting glucose and $\mathrm{HbA} 1 \mathrm{c}$ level. More recently, Aronson et al ${ }^{55}$ demonstrated that mean fasting blood glucose level was a better independent predictor of long-term mortality than baseline or final fasting blood glucose level. Patients whose fasting blood glucose levels were elevated on admission and improved during hospitalization had a better prognosis than those whose fasting blood glucose level remained persistently elevated, but patients with normal admission fasting blood glucose level had the best prognosis. This suggests that even transient hyperglycemia can have a negative impact in the setting of AMI.

\section{Abnormal Oral Glucose Tolerance Testing Predicts Long-Term Mortality}

The European guidelines recommend that patients presenting with AMI and no known history of diabetes undergo a formal assessment of glucometabolic status using an oral glucose tolerance test. This recommendation is based on a 2004 study by Bartnik et al ${ }^{56}$ prospectively evaluating 168 patients presenting with AMI, no known history of diabetes and admission glucose level of $<200 \mathrm{mg} / \mathrm{dL}$ who had an oral glucose tolerance test performed before hospital discharge. On median follow-up of 34 months, there was a significantly higher rate of major cardiovascular events, defined as a composite of cardiovascular death, nonfatal myocardial infarction, nonfatal stroke or severe heart failure, in patients with abnormal oral glucose tolerance testing.

\section{Treatment}

Treatment of hyperglycemia in nondiabetics in the setting of AMI remains controversial. Because spontaneous improvement in fasting blood glucose level is noted in some patients, it is possible that the initial use of insulin may lead to an increased risk of hypoglycemic events as the underlying metabolic status improves.

\section{Lessons From the Diabetic Population in the Diabetes and Insulin-Glucose Infusion in Acute Myocardial Infarction Studies}

In the diabetes and insulin-glucose infusion in acute myocardial infarction (DIGAMI) study, 620 AMI diabetic patients were randomized to receive either intensive insulin treatment or routine diabetic therapy. ${ }^{57}$ Higher glucose concentrations on admission were shown to predict a higher risk of mortality, and after a mean follow-up of 3.4 years, blood glucose 
levels significantly improved and mortality significantly decreased in the intensive insulin treatment group. However, because patients in the treatment group were assigned to insulin both in the hospital and for 3 months after discharge, it was uncertain whether the inpatient or outpatient intervention was responsible for the significant reduction in mortality seen.

DIGAMI-2 attempted to further distinguish the cause of the mortality benefit seen in the original trial by randomizing 1253 diabetic patients presenting with AMI to acute insulinglucose infusion followed by insulin-based long-term glucose control, acute insulin-glucose infusion followed by standard long-term glucose control or routine management. ${ }^{58}$ Although no significant difference in mortality was noted, the study was statistically underpowered, reaching less than one half of its goal sample size, and there was an imbalance in numbers in the 3 groups. Furthermore, target blood glucose levels were not reached in the intensive treatment arm. Finally, there was a higher baseline blood glucose level and a greater initial decrease in blood glucose level in DIGAMI-1 than in DIGAMI-2, which may reflect that it was felt safer to lower a high blood glucose value than to normalize a lower one. Admission blood glucose level was confirmed in this study to be an independent predictor of mortality in diabetic AMI patients.

\section{Insulin Infusion in Nondiabetic Patients Presenting With Hyperglycemia in the Setting of AMI}

The Hi-5 study sought to determine whether tight glycemic control in 240 AMI patients presenting with glucose level $\geq 140 \mathrm{mg} / \mathrm{dL}$ reduced mortality. However, unlike the DIGAMI studies, the intervention was limited to the immediate postinfarct period. ${ }^{59}$ About one half of the patients randomized did not have a known history of diabetes. Although in-hospital, 3and 6-month mortality was not reduced, heart failure and reinfarction within 3 months was significantly reduced. Unfortunately, a significant difference in glucose levels between treatment and control arms was not achieved. When analyzed by mean glucose level, 6month mortality was noted to be significantly lower when the mean glucose level achieved was $\leq 44 \mathrm{mg} / \mathrm{dL}$ than when the mean glucose level achieved was >144 mg/dL. Furthermore, infarct size, as measured by creatine phosphokinase, was similar in the 2 groups, suggesting that elevated blood glucose level was not simply a marker of extensive cardiac damage.

\section{Insulin-Glucose-Potassium Infusion in Nondiabetic Patients Presenting With AMI}

Other studies have investigated the role of glucose, insulin and potassium infusions in AMI patients with the primary goal of delivering insulin, rather than controlling hyperglycemia. The largest of these studies, CREATE-ECLA, investigated the effect of glucose-insulinpotassium infusion in 20,201 diabetic and nondiabetic AMI patients. ${ }^{60}$ No mortality benefit was demonstrated. It was noted that this trial provided the best evidence that increasing admission glucose levels predicted mortality given its large sample size, but there was no requirement for stringent blood glucose control. In fact, the glucose levels in the treatment group were actually higher than those in the control group at 6 and 24 hours after randomization, despite equal values at baseline. The associated increase in mortality and heart failure in the first 3 days was attributed to the glucose-insulin-potassium infusion. 
In contrast, a smaller study analyzing early initiation of lower infusion rate of glucoseinsulin-potassium in 120 AMI patients demonstrated an $88 \%$ reduction in major cardiovascular events at 1 year follow-up. ${ }^{61}$ The majority of the patients studied in this trial had no history of diabetes.

\section{Future Directions}

Current guidelines do not address the frequency of glucose monitoring or specify therapy.

2,62 Point-of-care glucose monitoring allows for rapid results and implementation of treatment. Therefore, guidelines need to more clearly define how often blood glucose level monitoring should take place in the peri-infarct setting and how hyperglycemia should be managed. Hypoglycemia is arguably one of the most dangerous risks of acutely treating hyperglycemia. However, there are multiple validated protocols for insulin infusion to treat hyperglycemia, and in a carefully monitored setting tight glycemic control should be able to be safely achieved. Ensuring the safety of patients will have to include defining the most effective treatment protocols to be used in a closely monitored setting with rapid action in response to potential hypoglycemia.

Further investigation is needed to develop optimal medical therapy for nondiabetic AMI patients with hyperglycemia. Studies that include measurements of serum catecholamines, cortisol, free fatty acid, growth hormone, insulin and glucagon levels, along with an oral glucose tolerance test after discharge from the hospital, would help to elucidate the underlying pathophysiology of hyperglycemia in this population. A randomized trial of intensive insulin therapy alone rather than a glucose-insulin-potassium infusion is warranted.

\section{Summary}

Hyperglycemia is common in nondiabetic patients with AMI, is associated with inflammation, a prothrombotic state and depressed myocardial contractility and is an independent predictor of mortality. Fasting blood glucose level correlates better with mortality than random glucose level, suggesting that fasting blood glucose level may reflect an underlying abnormal metabolic state. Other lines of evidence suggest that hyperglycemia in nondiabetic patients with AMI may in part be due to a transient stress-induced phenomenon. Blood glucose levels should be monitored closely in patients presenting with AMI, regardless of diabetic status and, based on the limited current evidence, consideration should be taken to maintain blood glucose level in the range of 100 and $140 \mathrm{mg} / \mathrm{dL}$.

\section{REFERENCES}

1. Qaseem A, Humphrey LL, Chou R, et al., on behalf of the Clinical Guidelines Committee of the American College of Physicians. Use of intensive insulin therapy for the management of glycemic control in hospitalized patients: a clinical practice guideline from the American College of Physicians. Ann Intern Med 2011;154:260-7. [PubMed: 21320941]

2. Kushner FG, Hand M, Smith SC, et al. 2009 Focused updates: ACC/AHA guidelines for the management of patients with ST-elevation myocardial infarction and ACC/AHA/SCAI guidelines on percutaneous coronary intervention: a report of the American College of Cardiology Foundation/ American Heart Association task force on practice guidelines. J Am Coll Cardiol 2009;54:2205-41. [PubMed: 19942100] 
3. Levine SA. Coronary thrombosis; its various clinical features. Medicine 1929;8:245-418.

4. Haffner SM, Stern MP, Hazuda HP, et al. Cardiovascular risk factors in confirmed prediabetic individuals. Does the clock for coronary heart disease start ticking before the onset of clinical diabetes? JAMA 1990;263:2893-8. [PubMed: 2338751]

5. Norhammar A, Tenerz A, Nilsson G, et al. Glucose metabolism in patients with acute myocardial infarction and no previous diagnosis of diabetes mellitus: a prospective study. Lancet 2002;359:2140-4. [PubMed: 12090978]

6. Wahab NN, Cowden EA, Pearce NJ, et al. Is blood glucose an independent predictor of mortality in acute myocardial infarction in the thrombolytic era? J Am Coll Cardiol 2002;40:1748-54. [PubMed: 12446057]

7. Bolk J, van der Ploeg TJ, Cornel JH, et al. Impaired glucose metabolism predicts mortality after a myocardial infarction. Int J Cardiol 2001;79:207-14. [PubMed: 11461743]

8. Ravid M, Berkowicz M, Sohar E. Hyperglycemia during acute myocardial infarction. A six-year follow-up study. JAMA 1975;233:807-9. [PubMed: 1173880]

9. Soler NG, Frank S. Value of glycosylated hemoglobin measurements after acute myocardial infarction. JAMA 1981;246:1690-3. [PubMed: 7277644]

10. Lakhdar A, Stromberg P, McAlpine SG. Prognostic importance of hyperglycemia induced by stress after acute myocardial infarction. Br Med J 1984;288:288. [PubMed: 6419901]

11. Tenerz A, Lonnberg I, Berne C, et al. Myocardial infarction and prevalence of diabetes mellitus. Is increased casual blood glucose at admission a reliable criterion for the diagnosis of diabetes? Eur Heart J 2001;22:1102-10. [PubMed: 11428850]

12. American Diabetes Association. Diagnosis and classification of diabetes mellitus. Diabetes Care 2010;33:S62-9. [PubMed: 20042775]

13. McDonald L, Baker C, Bray C. Plasma catecholamines after cardiac infarction. Lancet 1969;2:1021-3. [PubMed: 4187539]

14. Lykonsky PE, Oganov RG. Blood plasma catecholamines and their urinary excretion in patients with acute myocardial infarction. Am Heart J 1972;83:182-8. [PubMed: 4110092]

15. Karlsberg PP, Cryer PE, Roberts R. Serial plasma catecholamines response early in the course of clinical acute myocardial infarction: relation to infarct extent and mortality. Am Heart J 1981;102:24-9. [PubMed: 7246410]

16. Prakash R, Parmley NW, Horkat M. Serum cortisol, plasma free fatty acids and urinary catecholamines as indicators of complications in acute myocardial infarction. Circulation 1972;45:736-45. [PubMed: 5016012]

17. Burckhardt P, Felber JP, Peret C. Adrenocortical, insulin and met abolic changes in response to acute myocardial infarction. Helv Med Acta 1972;36:277-93. [PubMed: 4636279]

18. Bailey RR, Abernthy MH, Beaven DW. Adrenocortical response to the stress of acute myocardial infarction. Lancet 1967;1:970-3. [PubMed: 4164602]

19. Bloom SR, Daniel PM, Johnson DI. Release of glucagon induced by stress. Q J Exp Physiol Cogn Med Sci 1973;58:99-108. [PubMed: 4631751]

20. Willerson JT, Hutcheson DR, Leshin SJ, et al. Serum glucagon and insulin levels and their relationship to blood glucose values in patients with acute myocardial infarction and acute coronary insufficiency. Am J Med 1974;57:747-53. [PubMed: 4440699]

21. Taylor SH, Majind PA, Gosh P. Insulin secretion following myocardial infarction. Lancet 1969;2:1373-7. [PubMed: 4188271]

22. Dykes JRW, Saxton c, Taylor SH. Insulin secretion in cardiogenic shock. Br Med J 1969;2:490-3. [PubMed: 5771581]

23. Vetter NJ. Initial metabolic and hormonal response to acute myocardial infarction. Lancet 1974;1:284-8. [PubMed: 4130473]

24. Oswald GA, Smith CCT, Betteridge DJ, et al. Determinants and importance of stress hyperglycemia in non-diabetic patients with myocardial infarction. Br Med J 1986;293:917-22. [PubMed: 3094714]

25. Shechter M, Merz CN, Paul-Labrador MJ, et al. Blood glucose and platelet-dependent thrombosis in patients with coronary artery disease. J Am Coll Cardiol 2000;35:300-7. [PubMed: 10676673] 
26. Guyader AL, Pacheco G, Seaver N, et al. Inhibition of platelet GPIIb-IIIa and P-selectin expression by aspirin is impaired by stress hyperglycemia. J Diabetes Complications 2009;23:65-70. [PubMed: 18413191]

27. Davi G, Catalano I, Averna M, et al. Thromboxane biosynthesis and platelet function in type II diabetes mellitus. N Engl J Med 1990;322: 1769-74. [PubMed: 2345567]

28. Juhan-Vague I, Alessi MC, Vague P. Increased plasma plasminogen activator inhibitor 1 levels: a possible link between insulin resistance and atherothrombosis. Diabetologia 1991;34:457-62. [PubMed: 1916049]

29. Schneider DJ, Nordt TK, Sobel BE. Attenuated fibrinolysis and accelerated atherogenesis in type 2 diabetic patients. Diabetes 1993;42: 1-7. [PubMed: 8420806]

30. Williams SB, Goldfine AB, Timimi FT, et al. Acute hyperglycemia attenuates endotheliumdependent vasodilation in humans in vivo. Circulation 1998;97:1695-1701. [PubMed: 9591763]

31. Kawano H, Motoyama T, Hirashima O, et al. Hyperglycemia rapidly suppresses flow-mediated endothelium-dependent vasodilation of brachial artery. J Am Coll Cardiol 1999;34:146-54. [PubMed: 10400004]

32. Brownlee M, Cerami A, Vlassara H. Advanced glycosylation end products in tissue and the biochemical basis of diabetic complications. N Engl J Med 1990;322:1769-74. [PubMed: 2345567]

33. Nishikawa T, Edelstein D, Du XL, et al. Normalizing mitochondrial superoxide production blocks three pathways of hyperglycemic damage. Nature 2000;404:787-90. [PubMed: 10783895]

34. Esposito K, Nappo F, Marfella R, et al. Inflammatory cytokine concentrations are acutely increased by hyperglycemia in humans: role of oxidative stress. Circulation 2002;106:2067-72. [PubMed: 12379575]

35. Nappo F, Esposito K, Cioffi M, et al. Postprandial endothelial activation in healthy subjects and in type 2 diabetic patients: role of fat and carbohydrate meals. J Am Coll Cardiol 2002;39:1145-50. [PubMed: 11923038]

36. Iwakura K, Ito H, Ikushima M, et al. Association between hyperglycemia and the no-reflow phenomenon in patients with acute myocardial infarction. J Am Coll Cardiol 2003;41:1-7. [PubMed: 12570936]

37. Marfella R, Siniscalchi M, Esposito K, et al. Effects of stress hyperglycemia on acute myocardial infarction: role of inflammatory immune process in functional cardiac outcome. Diabetes Care 2003; 26:3129-35. [PubMed: 14578250]

38. Marfella R, Filippo CD, Portoghese M, et al. Tight glycemic control reduces heart inflammation and remodeling during acute myocardial infarction in hyperglycemic patients. J Am Coll Cardiol 2009;53:1425-36. [PubMed: 19371826]

39. Ishihara M, Inoue I, Kawagoe T, et al. Effect of acute hyperglycemia on the ischemic preconditioning effect of prodromal angina pectoris in patients with a first anterior wall acute myocardial infarction. Am J Cardiol 2003;92:288-91. [PubMed: 12888134]

40. Holubarasch C, Ruf T, Goldstein DJ, et al. Existence of the Frank-Starling mechanism in the failing human heart: investigation on the organ, tissue, and sarcomere levels. Circulation 1996;94:683-9. [PubMed: 8772688]

41. Oliver MF, Opie LH. Effects of glucose and fatty acids on myocardial ischemia and arrhythmias. Lancet 1994;343:155-8. [PubMed: 7904009]

42. Eberli FR, Weinberg EO, Grice WN, et al. Protective effect of increased glycolytic substrate against systolic and diastolic dysfunction and increased coronary resistance from prolonged global underperfusion and reperfusion in isolated rabbit hearts perfused with erythrocyte suspensions. Circ Res 1991;68:466-81. [PubMed: 1991351]

43. Mjos OD. Effect of free fatty acids on myocardial function and oxygen consumption in intact dogs. J Clin Investig 1971;50:1386-9. [PubMed: 5090055]

44. Leor J, Goldbourt U, Reicher-Reiss H, et al. Cardiogenic shock complicating acute myocardial infarction in patients without heart failure on admission: incidence, risk factors, and outcome. Am J Med 1993;94:265-73. [PubMed: 8452150] 
45. Capes SE, Hunt D, Malmberg K, et al. Stress hyperglycemia and increased risk of death after myocardial infarction in patients with and without diabetes: a systematic overview. Lancet 2000;355:773-8. [PubMed: 10711923]

46. Stranders I, Diamant M, van Gelder RE, et al. Admission glucose level as risk indicator of death after myocardial infarction in patients with and without diabetes mellitus. Arch Intern Med 2004;164:982-8. [PubMed: 15136307]

47. Bellodi G, Manicardi V, Malavasi V, et al. Hyperglycemia and prognosis of acute myocardial infarction in patients without diabetes mellitus. Am J Cardiol 1989;64:885-8. [PubMed: 2801556]

48. Norhammar AM, Ryden L, Malmberg K. Admission plasma glucose. Independent risk factor for long-term prognosis after myocardial infarction even in non-diabetic patients. Diabetes Care 1999; 22:1827-31. [PubMed: 10546015]

49. Timmer JR, Van der Horst IC, Ottervanger JP, et al. Prognostic value of admission glucose in nondiabetic patients with myocardial infarction. Am Heart J 2004;148:399-404. [PubMed: 15389225]

50. Straumann E, Kurz DJ, Muntwyler J, et al. Admission glucose concentrations independently predict early and late mortality in patients with acute myocardial infarction treated by primary or rescue percutaneous coronary intervention. Am Heart J 2005;150:1000-6. [PubMed: 16290985]

51. Gasior M, Pres D, Stasik-Pres G, et al. Effect of blood glucose levels on prognosis in acute myocardial infarction in patients with and without diabetes, undergoing percutaneous coronary intervention. Cardiol J 2008;15:422-30. [PubMed: 18810716]

52. Kosiborod M, Rathore SS, Inzucchi SE, et al. Admission glucose and mortality in elderly patients hospitalized with acute myocardial infarction: implications for patients with and without recognized diabetes. Circulation 2005;111:3078-86. [PubMed: 15939812]

53. Suleiman M, Hammerman H, Boulos M, et al. Fasting glucose is an independent risk factor for 30day mortality in patients with acute myocardial infarction: a prospective study. Circulation 2005;111: 754-60. [PubMed: 15699267]

54. Lavi S, Kapeliovich M, Grugberg L, et al. Hyperglycemica during acute myocardial infarction in patients who are treated by primary percutaneous coronary intervention: impact on long-term prognosis. Int J Cardiol 2008;123:117-22. [PubMed: 17367882]

55. Aronson D, Hammerman H, Suleiman M, et al. Usefulness of changes in fasting glucose during hospitalization to predict long-term mortality in patients with acute myocardial infarction. Am J Cardiol 2009;104:1013-7. [PubMed: 19801016]

56. Bartnik M, Malmberg K, Norhammar A, et al. Newly detected abnormal glucose tolerance: an important predictor of long-term outcome after myocardial infarction. Eur Heart J 2004;25:19907. [PubMed: 15541834]

57. Malmberg K, Norhammar A, Wedel H, et al. Glycometabolic state at admission: important risk marker of mortality in conventionally treated patients with diabetes mellitus and acute myocardial infarction: long-term results from the diabetes and insulin-glucose infusion in acute myocardial infarction (DIGAMI) study. Circulation 1999;99:2626-32. [PubMed: 10338454]

58. Malmberg K, Ryden L, Wedel H, et al. Intense metabolic control by means of insulin in patients with diabetes mellitus and acute myocardial infarction (DIGAMI 2): effects on mortality and morbidity. Eur Heart J 2005;26:650-61. [PubMed: 15728645]

59. Cheung NW, Wong VW, McLean M. The hyperglycemia: intensive insulin infusion in infarction (HI-5) study. A randomized controlled trial of insulin infusion therapy for myocardial infarction. Diabetes Care 2006;29:765-70. [PubMed: 16567812]

60. Mehta SR, Yusuf S, Diaz R, et al. Effect of glucose-insulin-potassium infusion on mortality in patients with acute ST-segment elevation myocardial infarction: the CREATE-ECLA randomized controlled trial. JAMA 2005;293:437-46. [PubMed: 15671428]

61. Krljanac G, Vasiljevic Z, Radovanovic M. Effects of glucose-insulin-potassium infusion on STelevation myocardial infarction in patients treated with thrombolytic therapy. Am J Cardiol 2005;96:1053-8. [PubMed: 16214437]

62. Moghissi ES, Korytkowski MT, DiNardo M, et al. American Association of Clinical Endocrinologists and American Diabetes Association consensus statement on inpatient glycemic control. Diabetes Care 2009;32:1119-31. [PubMed: 19429873] 


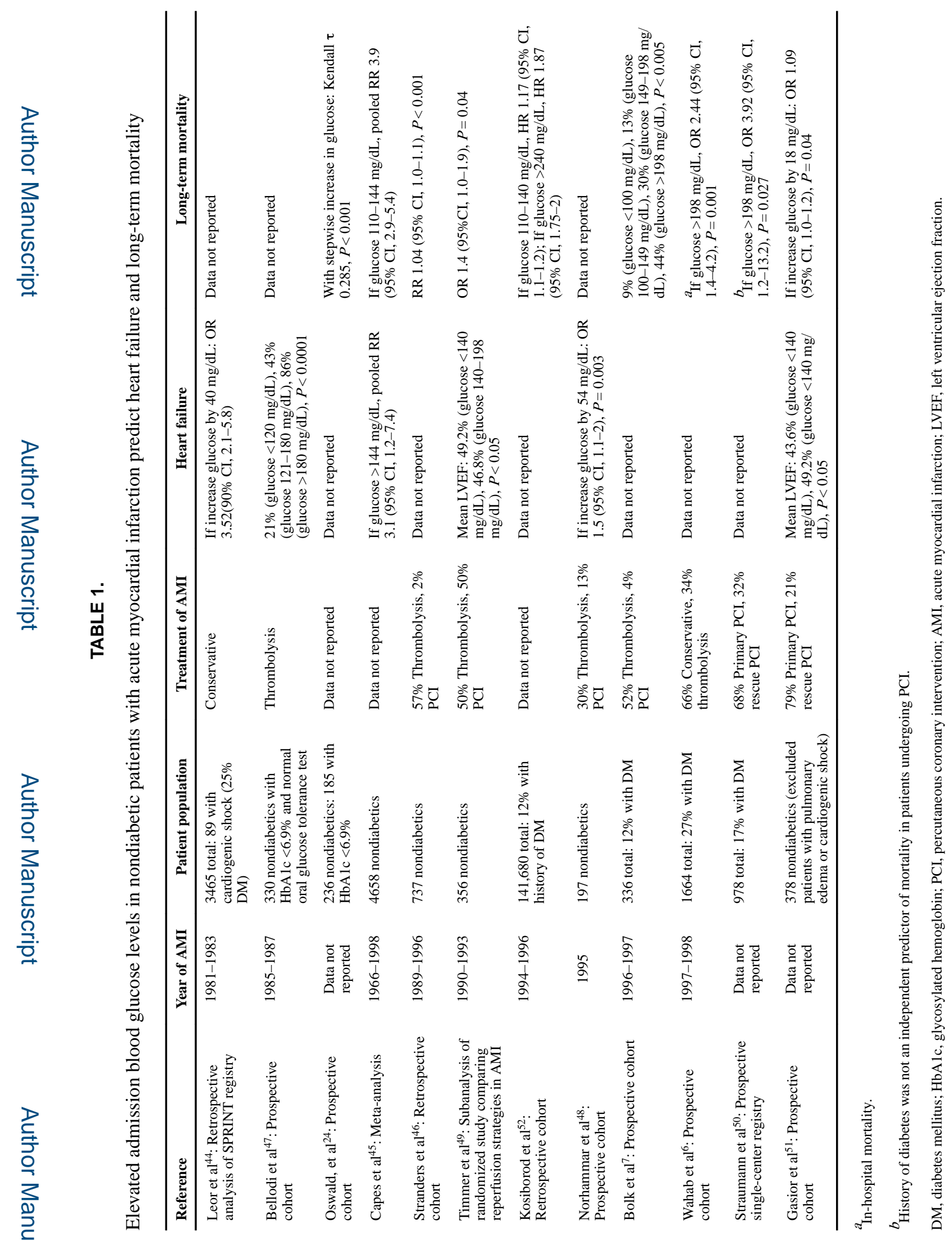

Am J Med Sci. Author manuscript; available in PMC 2019 November 06. 


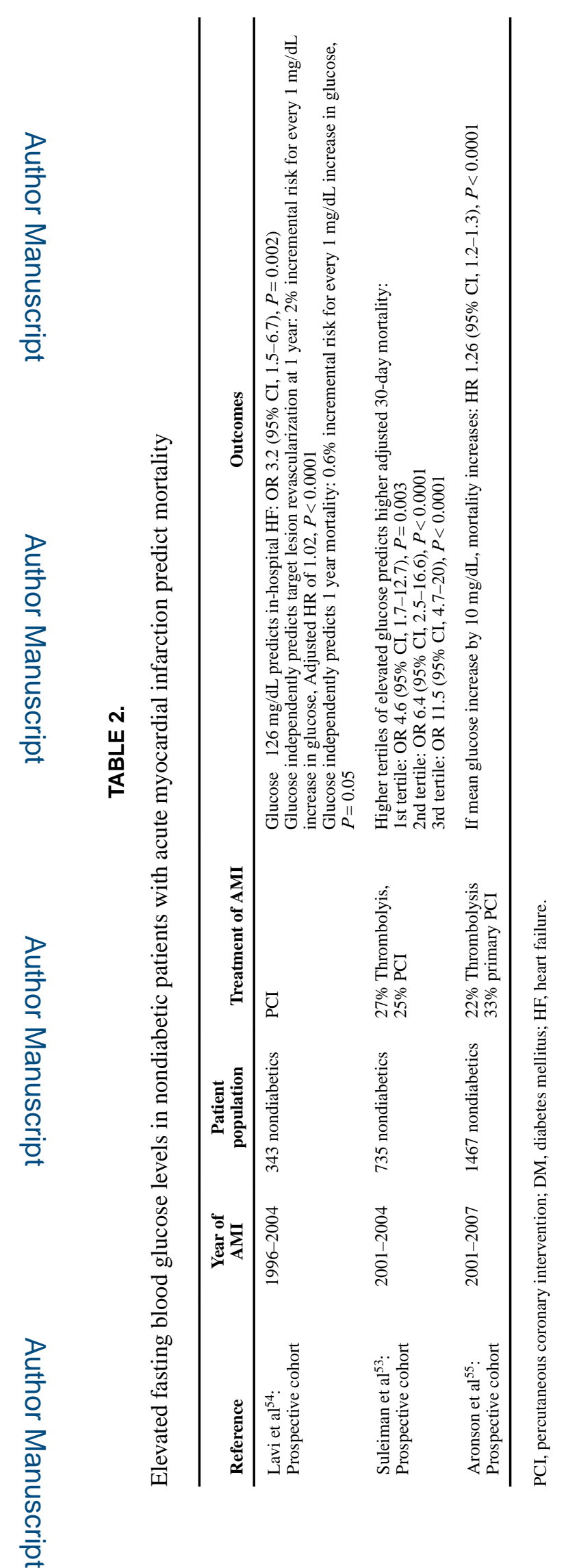

Am J Med Sci. Author manuscript; available in PMC 2019 November 06. 